\title{
Linear trends of the length of snow-cover season in the Northern Hemisphere as observed by the satellites in the period 1972-2000
}

\author{
Kunio RIKIISHI, Eisuke HASHIYA, Masafumi IMAI \\ Department of Earth and Environmental Sciences, Hirosaki University, Hirosaki 036-8561, Japan \\ E-mail: rikiiship@cc.hirosaki-u.ac.jp
}

\begin{abstract}
The dataset of Northern Hemisphere EASE-Grid weekly snow cover and sea-ice extent (U.S. National Snow and Ice Data Center) for the period September 1972-August 2000 is analyzed to examine the possible influence of recent global warming on the seasonal change of snow cover in the Northern Hemisphere. It is found that the total snow-cover area in the 1980s and 1990s is diminished by $3 \times 10^{6} \mathrm{~km}^{2}$, and the length of snow-cover season is reduced by $2-3$ weeks, as compared with the 1970s. In general, the contribution from earlier snowmelt is greater than that from delayed snow accumulation. In addition, the maximum snow-cover area during January-February has gradually decreased by about $3 \times 10^{6} \mathrm{~km}^{2}$ within the two decades. Geographically, the rate of decrease of snow-cover duration is $<0.1$ week per year (wpy) in the high-latitude regions such as the Siberian Plains and Northwest Territories of Canada and $>0.2$ wpy in the high-elevation regions such as the Scandinavian Peninsula, Tibetan Plateau and Rocky Mountains. The earlier snowmelt in the high-elevation regions suggests that the snowfall amounts there are decreasing owing to global warming.
\end{abstract}

\section{INTRODUGTION}

Snow cover is seasonally seen in high-latitude and/or highelevation regions in the Northern Hemisphere. As is well known, snow cover reflects much of the solar energy into space, and works as an insulator between the atmosphere and the land surface. In addition, significant heat is absorbed from the atmosphere through the snowmelting processes in spring and summer. Accordingly, snow cover plays an important role in the thermodynamics and dynamics of the atmosphere. Indeed, the variation in snow-cover extent is often associated with a large-scale variation in the atmospheric circulation such as the Indian monsoon (Hahn and Shukla, 1976; Kripalani and Kulkarni, 1999).

In the studies of snow-cover-climate interaction, many scientists have analyzed historical observations of snow depth or satellite observations of snow-cover extent over the Eurasian and/or North American continents and observed significant negative correlations between air temperature and snow-cover extent (Foster and others, 1983; Robinson and Dewey, 1990; Karl and others, 1993; Leathers and Robinson, 1993; Groisman and others, 1994; Fallot and others, 1997; Brown, 2000). On the other hand, Iwasaki (1991) and Gutzler and Rosen (1992) decomposed the temporal and spatial variations in snow-cover extent into major spatial patterns and related them to large-scale teleconnection patterns. According to the report from the Intergovernmental Panel on Climate Change (IPCC; Houghton and others 1996), the late 1980s through early 1990s is the decade when the global mean temperature increased most significantly in the 20th century. It is thus natural to expect that global warming may exert significant influence on the snow-cover extent, snowfall amount and seasonal change of the snow cover in the Northern Hemisphere. In fact, there are some papers discussing the recent decrease in snow-cover extent in connection with global warming (Robinson and Dewey, 1990; Karl and others, 1993; Robinson and others, 1993).

The objective of this paper is therefore to examine the possible influence of global warming on the seasonal change of snow cover by using satellite observations for the period 1972-2000. Decadal changes in the snow-cover area in the Northern Hemisphere will be examined first, and then the mean dates of first and last snow cover of a year and the mean length of a snow-cover season will be presented. Finally, linear (or secular) trends of the above three parameters will be studied, with focuses on the difference between the high and mid-latitudes, between the high and low elevations and between the Eurasian and American continents.

\section{DATA AND THREE PARAMETERS FOR SEASONAL SNOW GOVER}

Weekly snow-cover charts for the Northern Hemisphere, obtained from visible satellite images, have been published since 1966 by the U.S. National Oceanic and Atmospheric Administration (NOAA). The spatial resolution of satellite images is as precise as $1 \mathrm{~km} \times 1 \mathrm{~km}$ since the introduction of the Very High Resolution Radiometer (VHRR) in 1972. Although microwave sensors such as the Special Sensor Microwave/Imager (SSM/I) are also useful to determine snow-cover extents as well as snow depths, visible-band images are more reliable than microwave-band images in determining the border between snow-covered and snow- 


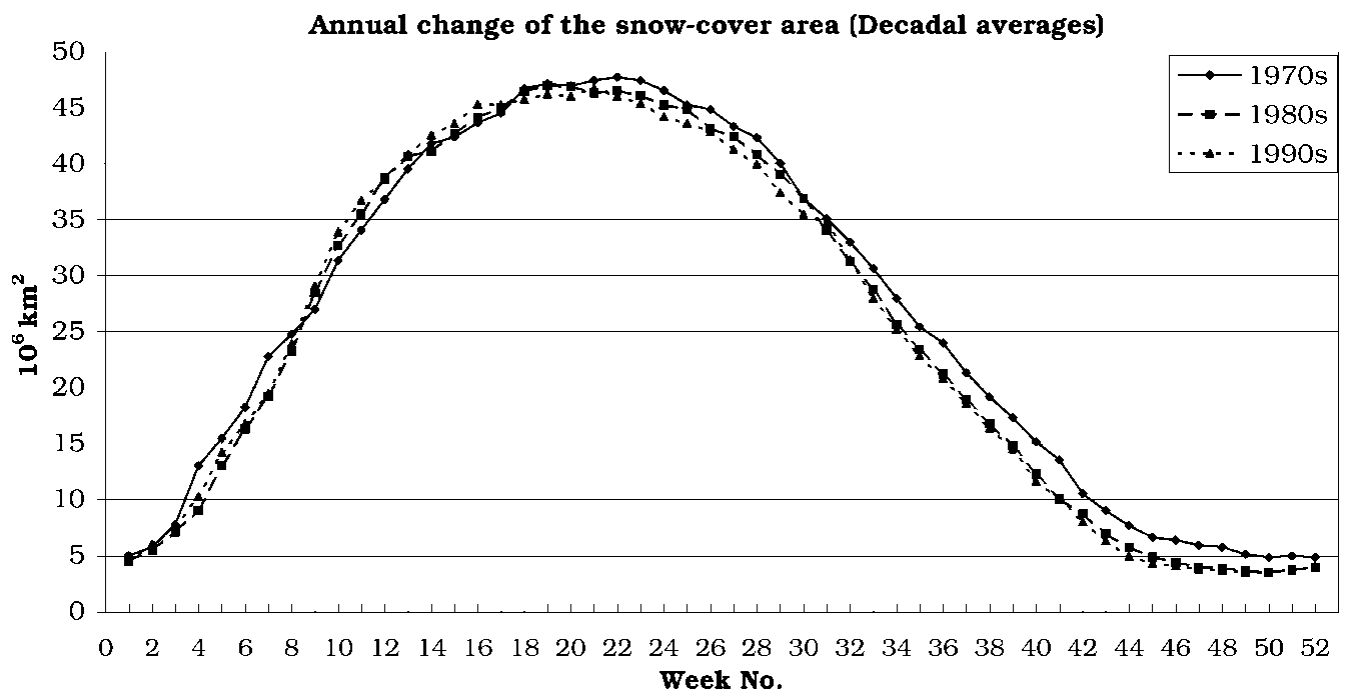

Fig. 1. Mean seasonal changes of the total snow-cover area for the 1970s, 1980s and 1990s (1970s: September 1972-August 1980; 1980s: September 1980-August 1990; 1990s: September 1990-August 2000).

free areas (Robinson and others, 1993; Armstrong and Brodzik, 2001).

The U.S. National Snow and Ice Data Center (NSIDG) has compiled the historical snow-cover charts to produce the dataset of Northern Hemisphere EASE-Grid weekly snow cover and sea-ice extent on CD-ROM (EASE: an acronym for Equal-Area SSM/I Earth Grid). In this dataset, a $25 \mathrm{~km} \times 25 \mathrm{~km}$ grid is regarded as "snow-covered" when $>50 \%$ of the grid area is snow-covered, and as "snow-free" otherwise. This original grid system is too fine, however, to examine the possible influence of global warming on a regional scale. We will therefore employ a new grid system of $1^{\circ}$ (lat.) $\times 2^{\circ}$ (long.) later. A new grid is regarded as "snowcovered" when $>70 \%$ of the grid area is snow-covered, and as "snow-free" otherwise. Through this procedure, spatially sporadic snow covers in the snowmelt period tend to be regarded as "snow-free". Snow covers around solitary mountains are also likely to be regarded as "snow-free".

The dataset analyzed here covers the period September 1972-August 2000. The data are given at intervals of a week, and it is reasonable to represent the seasonal change of snow cover as a function of week number. Here a snow-cover year is defined to start in September and end in the following August, because the total snow-cover area of the Northern Hemisphere reaches a minimum in August (see Fig. 1). For convenience, every snow-cover year is defined to consist of 52 weeks. Accordingly, the first week of a snow-cover year is defined to start within the period 1-7 September, and the 52nd week in late August. In case of a snow-cover year consisting of 53 weeks, the 53rd week is neglected. In case of a snow-cover year consisting of 51 weeks, the snow-cover extent in the 52nd week is assumed to be the same as in the 51st week. Possible errors arising from these procedures are negligible. Note that actual dates corresponding to a week number vary from year to year. The discussion below is based on the mean correspondences between the week numbers and calendar dates averaged over the 28 years. For example, the mean first week corresponds to the period 410 September, the mean 18th week to 1-7 January, and the mean 44 th week to $1-7$ July on average.

Important parameters representing the seasonal change of snow cover are the week numbers of first and last snow cover of a year and the length of a snow-cover season (number of snow-covered weeks). It is noted that, when a station is snow-covered consistently during a snow-cover year, the length of the snow-cover season is equivalent to the last minus first week number. If a station is snowcovered discontinuously during a snow-cover season, then the length of the snow-cover season is smaller than the last minus first week number.

\section{MEAN SEASONAL GHANGE OF THE TOTAL SNOW-COVER AREA AND SOME EXAMPLES OF INTERANNUAL VARIATIONS OF THE SEASONAL SNOW GOVER}

Snow cover is observed seasonally in the cold regions of the Northern Hemisphere, except Greenland and some mountain glaciers and ice caps. Characteristics of the seasonal change of snow cover depend on the latitude, elevation and geographical environment of the observational grid concerned. The total snow-cover area in the Northern Hemisphere can be obtained by counting the number of snowcovered grids (with an area of $25 \mathrm{~km} \times 25 \mathrm{~km}$ ). Figure 1 represents the mean seasonal change of the total snow-cover area for the 1970s, 1980s and 1990s. The total snow-cover area increases rapidly during the 5 th -15 th weeks (early October-mid-November), and decreases gradually during the 25th-40th weeks (late February-early June). The maximum value is usually observed during the 19 th-23rd weeks (mid-January-mid-February, about $47 \times 10^{6} \mathrm{~km}^{2}$ ), and the minimum value during the 49th-52nd weeks (August, about $3 \times 10^{6} \mathrm{~km}^{2}$ ). According to Oerlemans (2001), the total area of the ice sheet, glaciers and ice caps in the Northern Hemisphere amounts to $2.2 \times 10^{6} \mathrm{~km}^{2}$, which is slightly smaller than the minimum value of the total snow-cover area $\left(3 \times 10^{6} \mathrm{~km}^{2}\right)$. This may result from the analytical procedure by which a grid is regarded as "snow-covered" when $>50 \%$ of the grid area is snow-covered.

On inspecting the decadal changes, it is found that the snow accumulation in the 1980s and 1990s is delayed by about 1 week, and the snowmelt is advanced by about 2 weeks, compared to the 1970 s. Consequently, the length of a snow-cover season has decreased by about 3 weeks. In addition, the maximum snow-cover area during January- 

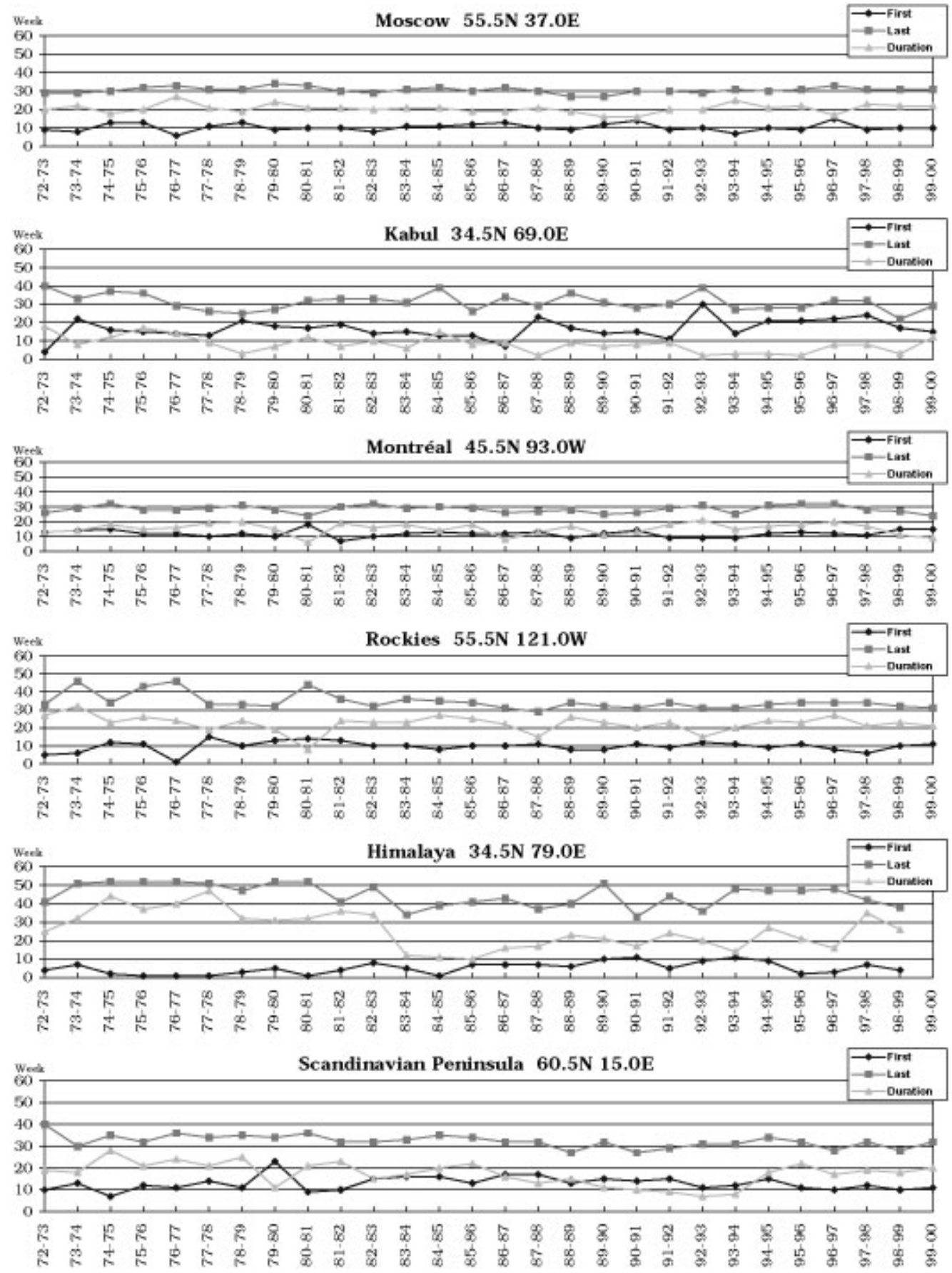

Fig. 2. Some examples of interannual variations of the week number of first and last snow cover and the snow-cover duration for six representative grids near Moscow, Russia; Kabul, Afghanistan; Montréal, Canada; the Rocky Mountains; the Himalaya; and the Scandinavian Peninsula. The center of each grid is indicated.

February has gradually decreased by about $3 \times 10^{6} \mathrm{~km}^{2}$ within the two decades. These facts may be manifestations of the influence of global warming on the snow-cover extent. The decreases in snow-cover extent for particular months or seasons have already been reported by Robinson and others (1990), Iwasaki (1991), Karl and others (1993), Brown (2000) and Armstrong and Brodzik (2001).

Generally speaking, snow cover is established during September-December and disappears during FebruaryJuly depending on climatic region. Figure 2 shows some examples of interannual variation of the week numbers of first and last snow cover and of the length of snow-cover season for six representative grids near Moscow, Kabul, Montréal, the Rocky Mountains, the Himalaya and the
Scandinavian Peninsula. For the high-latitude regions near Moscow and Montréal, none of the three parameters shows a clear trend. For the high-elevation region near Kabul, however, the week of last snow cover is advancing and the length of snow-cover season is decreasing. This tendency is more evident for the high-elevation regions near the Rocky Mountains and the Himalaya, where the length of snowcover season has decreased by several weeks during the period 1972-2000.

The above examples suggest that the influence of global warming on the seasonal change of snow cover differs significantly from one region to another. Therefore, geographical distributions of the above three parameters are examined below in detail. 


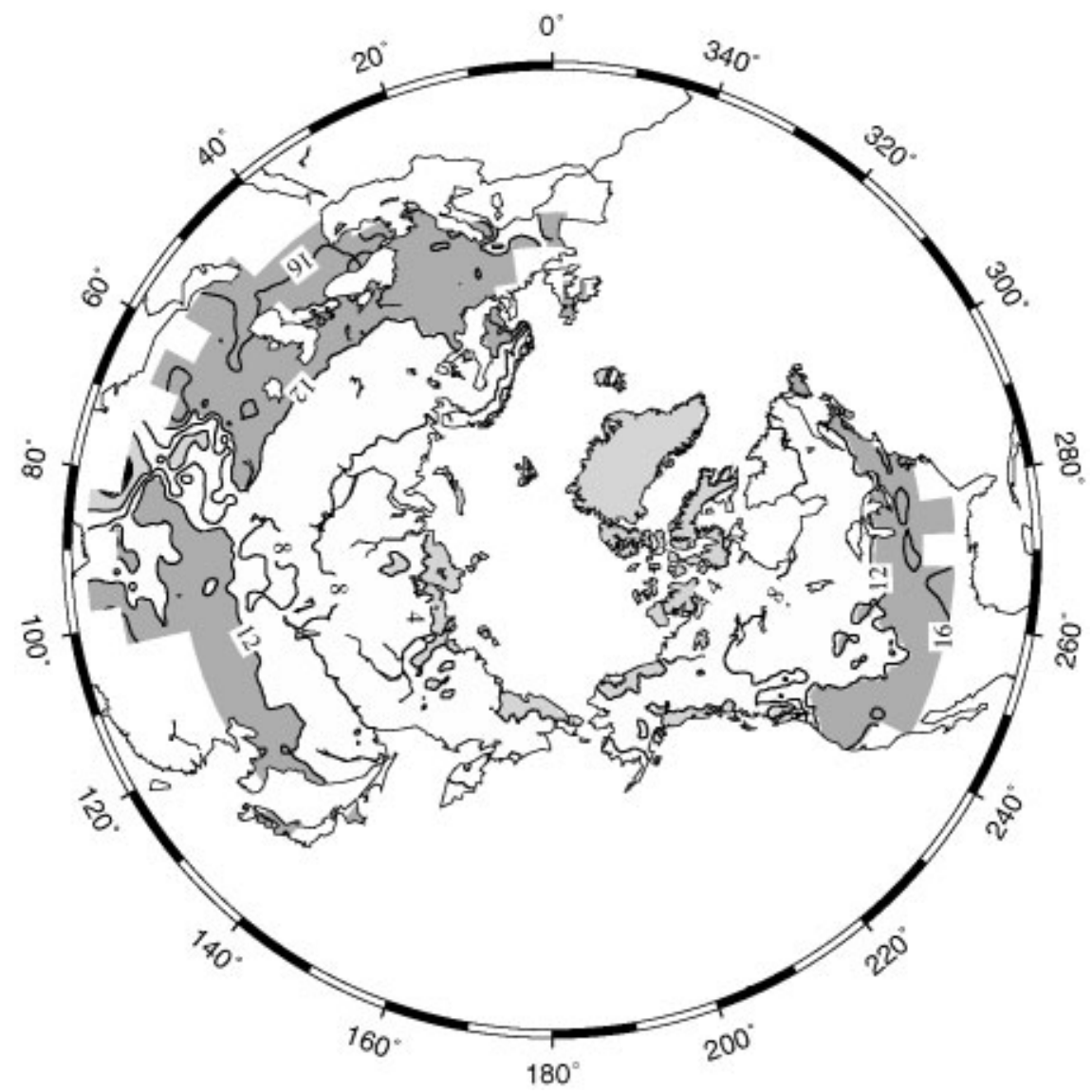

Fig. 3. Geographical distribution of the mean week numbers of first snow cover of a year. Isopleths are given at intervals of 4 weeks. The area with $<4$ weeks is lightly shaded, and the area with $>12$ weeks is heavily shaded.

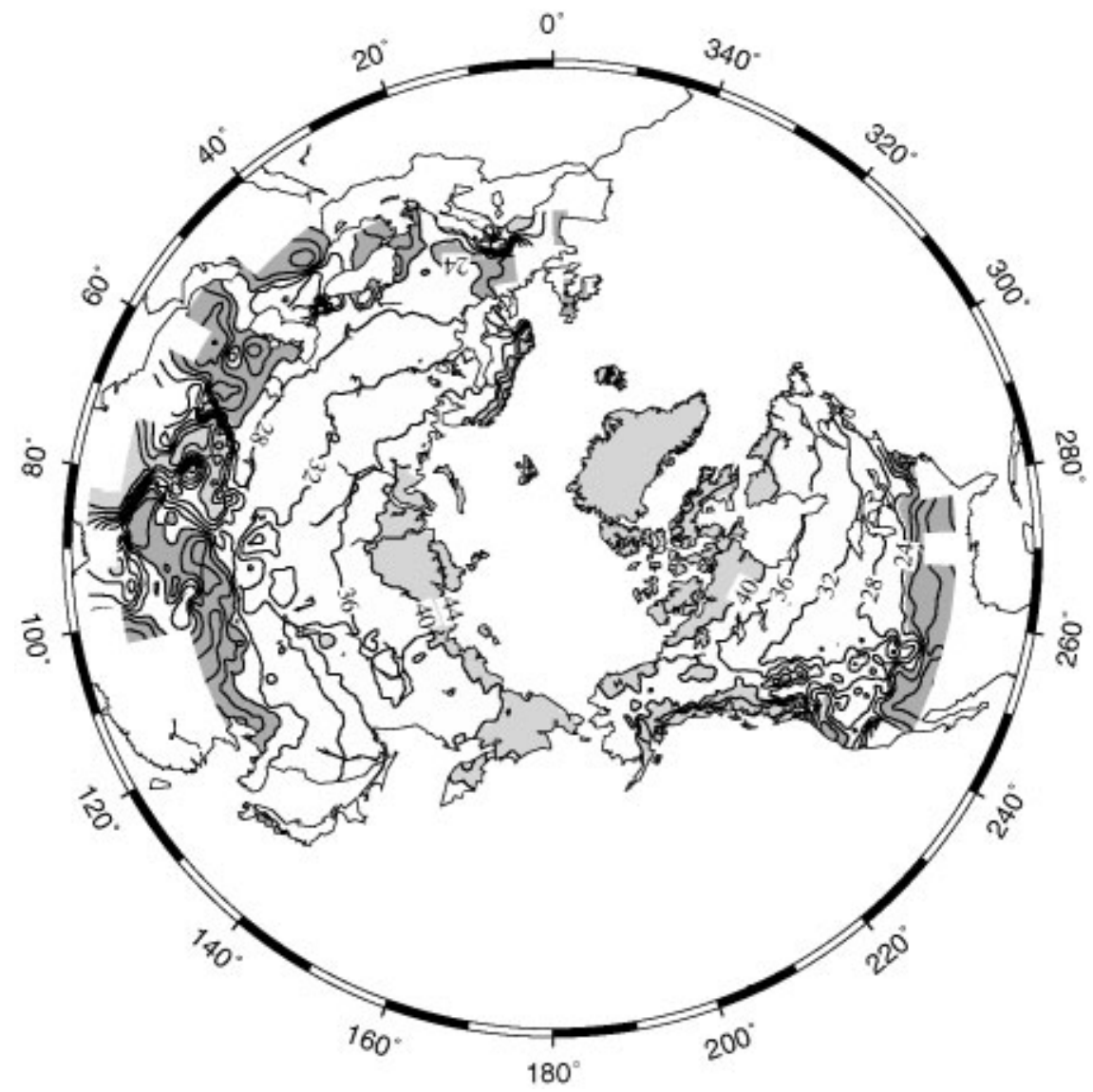

Fig. 4. Geographical distribution of the mean week numbers of last snow cover of a year. Isopleth are given at intervals of 4 weeks. The area with $>40$ weeks is lightly shaded, and the area with $<24$ weeks is heavily shaded. 


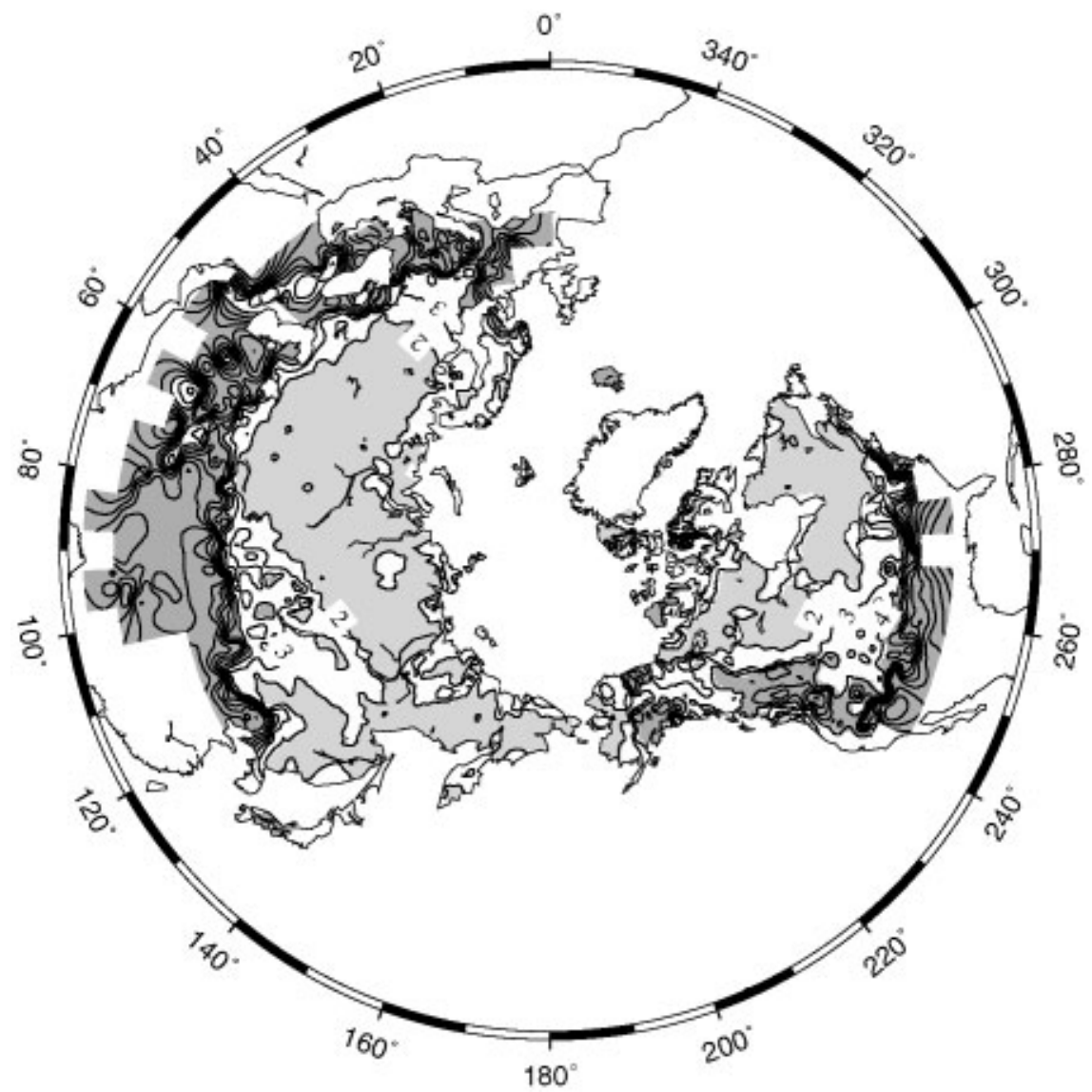

Fig. 5. Geographical distribution of the variability of the week number of last snow cover in terms of standard deviation. Isopleths are given at intervals of a week. The area with $<2$ weeks is lightly shaded, and the area with $>4$ weeks is heavily shaded.

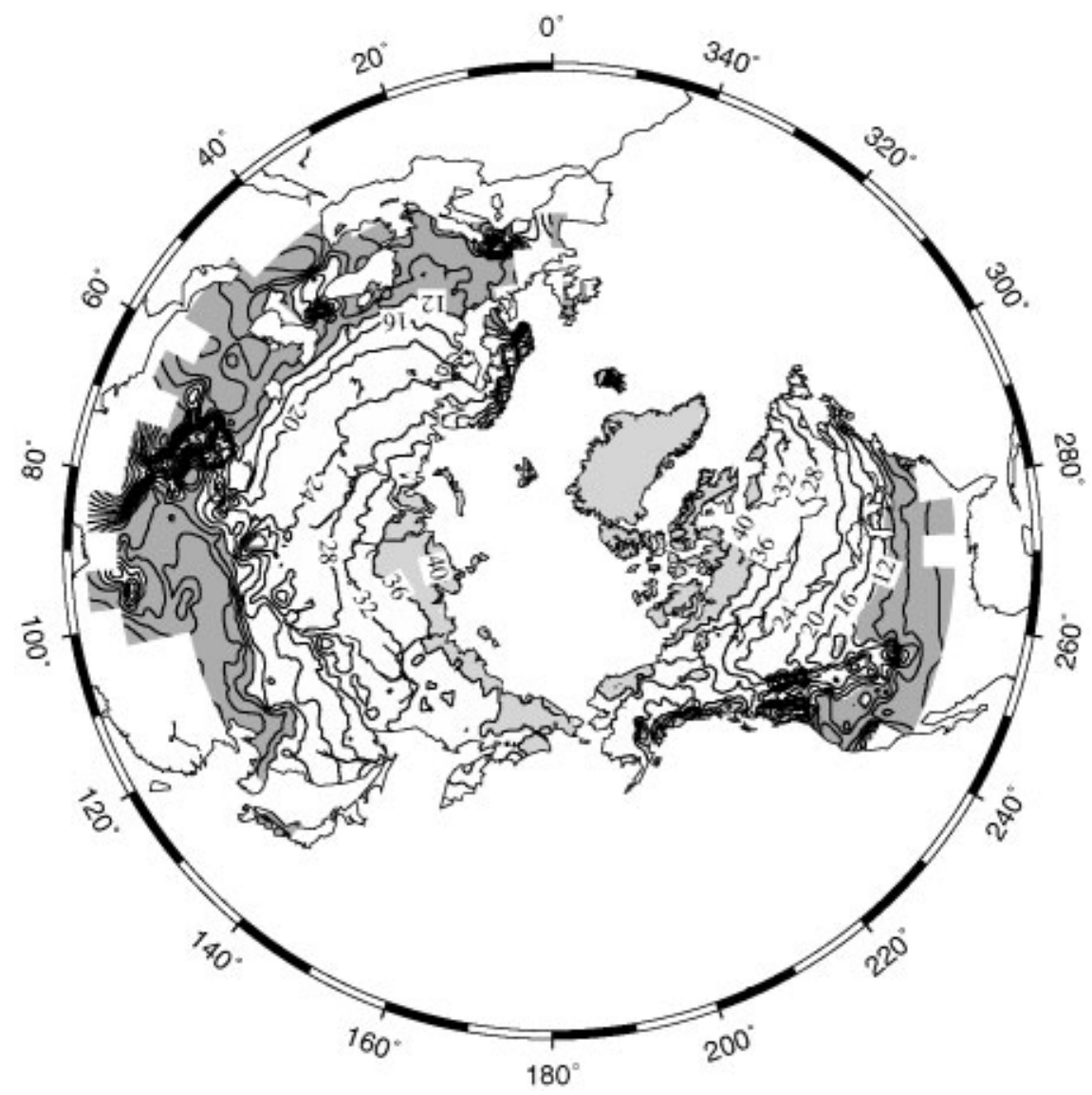

Fig. 6. Geographical distribution of the mean lengths of a snow-cover season. Isopleths are given at intervals of 4 weeks. The area with $>36$ weeks is lightly shaded, and the area with $<12$ weeks is heavily shaded. 


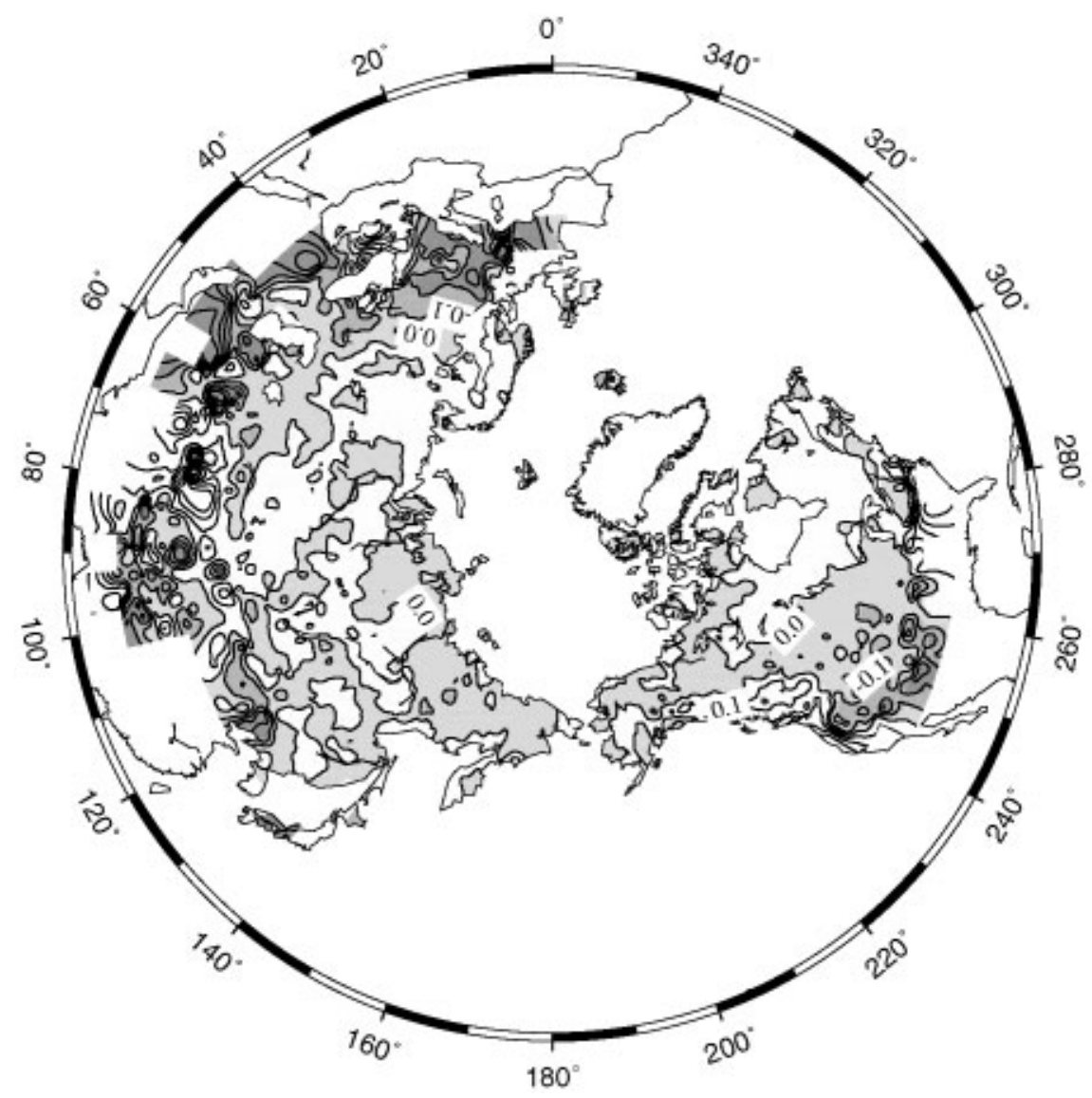

Fig. 7. Geographical distribution of the linear trends of the date of first snow cover of a year. Isopleths are given at intervals of 0.1 wpy. The areas with the values 0.0 to 1.0, -0.1 to -0.2 , and $<-0.2$ are shaded lightly, moderately and heavily, respectively, while the area with positive values is not shaded.

\section{MEAN DATES OF FIRST AND LAST SNOW COVER AND MEAN LENGTH OF SNOW-GOVER SEASON}

Snow cover is established every year in high-latitude regions but not every year in boundary regions located in the midlatitudes. To study the mean features of seasonal snow cover, therefore, only the grids for which snow cover was established for $>20$ years are considered here. Figure 3 shows the geographical distribution of the mean week numbers of first snow cover of a year. Along the Arctic coasts of central and eastern Siberia and Alaska, the snow cover is established by the 4 th week (late September). In the Eurasian continent, the snow-cover front (or snowline) rapidly progresses westward to the western Siberian Plain by the 8th week (late October) and to European Russia by the 12th week (late November). In the North American continent, the snow-cover front rapidly progresses southward to the Northwest Territories of Canada by the 8th week and to the Great Lakes by the 12th week. In most of the European Plains, snow cover is established in about the 12 th week (late November). In high-elevation regions near the Tibetan Plateau, snow cover is established by the 4th week and the snow-cover front comes down to the surrounding low-elevation regions.

In Figure 4, the geographical distribution of the mean week numbers of the last snow cover of a year is shown. Along the Siberian and Canadian Arctic coasts, the snow cover disappears in the 40th week (early June) or later. The Tibetan Plateau and its surroundings is another region of very late snowmelt. Generally speaking, the snowmelt front slowly progresses from the mid-latitudes to the high lati- tudes during the 32 nd-40th weeks (early April-early June) over the Eurasian continent or during the 28th-40th weeks (mid-March-early June) over the North American continent.

The variability of week number of the last snow cover is represented in Figure 5 in terms of standard deviation. The smallest values, $2-3$ weeks, are shown in the regions northward of $50^{\circ} \mathrm{N}$, and larger values of 5-10 weeks in mid-latitude and/or high-elevation regions. (Note that the variability of last snow-cover week is significantly larger than that of first snow-cover week, though the figure is not presented.) Obviously, the date of snow disappearance may depend on the total snowfall amount during the snow-cover season and on the mean air temperature during the snowmelt period. The higher (lower) temperature in wintertime is likely to decrease (increase) the snowfall amount. Indeed, Fallot and others (1997) reported that the precipitation and snow depth in mid-latitude regions were very sensitive to the air-temperature variation. On the other hand, higher (lower) temperature in springtime is likely to advance (delay) the snowmelt. It may be concluded that in mid-latitude plains and high mountain regions the air temperature is variable and the total snowfall amount varies considerably from year to year.

Finally, the geographical distribution of the mean length of a snow-cover season is presented in Figure 6. Northward of $50^{\circ} \mathrm{N}$ the snow-cover duration is longer than 20 weeks ( 5 months), and longer than 36 weeks (9 months) along the Arctic coasts and high-elevation regions. The perennial snow of glaciers and ice caps is also represented in the figure, though it is hard to see. It is noted that the standard 


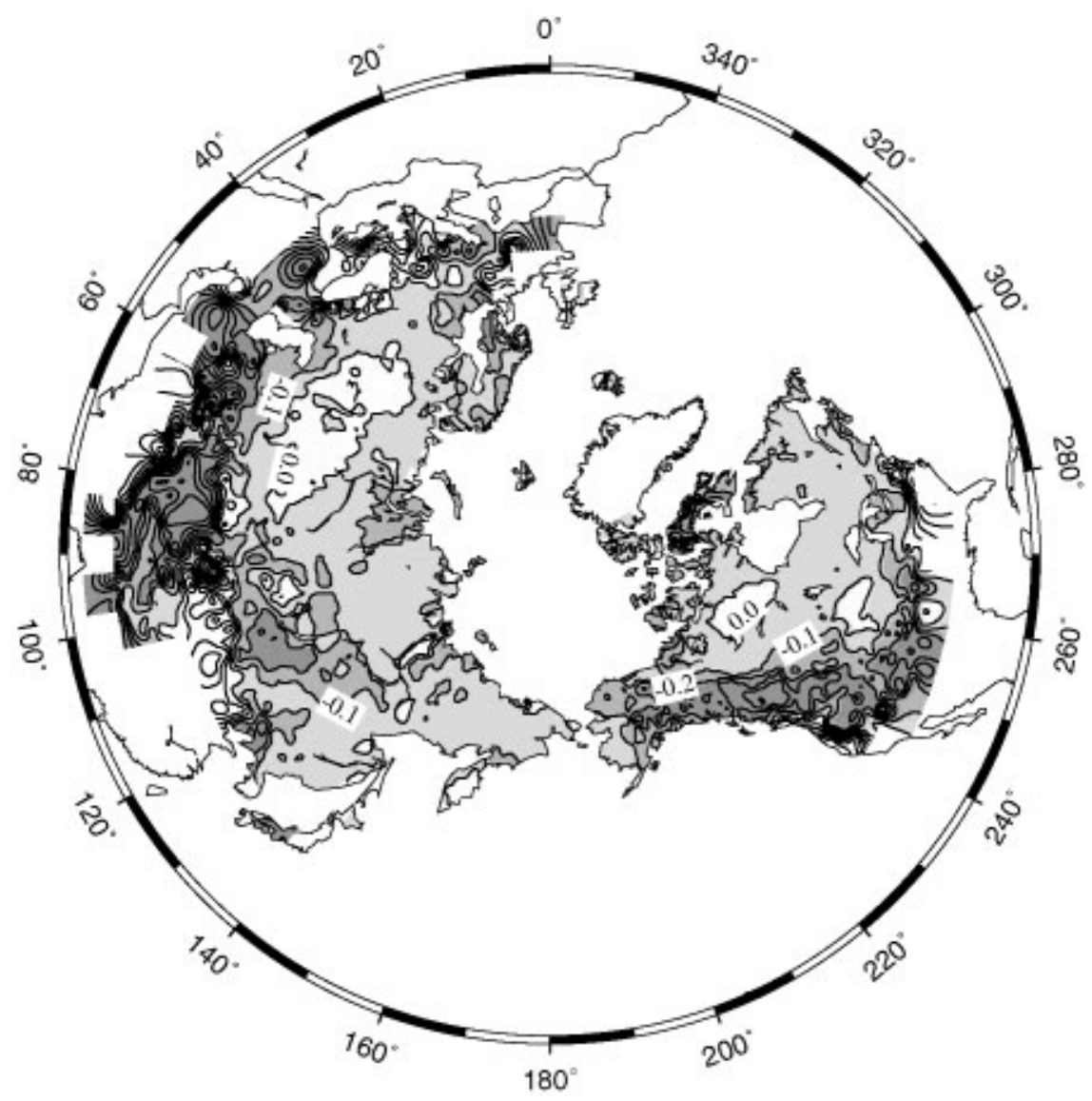

Fig. 8. Geographical distribution of the linear trends of the date of last snow cover of a year. Isopleths are given at intervals of 0.1 wpy. The areas with the values 0.0 to $-1.0,-0.1$ to -0.2 , and $<-0.2$ are shaded lightly, moderately and heavily, respectively, while the area with positive values is not shaded.

deviation of the length of a snow-cover season is generally smaller than that of the last snow-cover week, with values less than 3 weeks in most of the Northern Hemisphere (figure not presented).

\section{LINEAR TRENDS OF THE DATES OF FIRST AND LAST SNOW COVER AND THE LENGTH OF SNOW-COVER SEASON}

In general, possible temperature rise due to global warming is expected to delay the snow accumulation and advance the snowmelting as suggested in Figure 1. Accordingly, secular (linear) trends of the three parameters for seasonal snow cover have been examined for every grid by applying linear fitting to their interannual variations.

The geographical distribution of the linear trends of the date of first snow cover is shown in Figure 7. In the figure a positive value indicates that the start of the snow-cover season is delayed every year, and a negative value that it is advanced. Positive values of $<0.1$ week per year (wpy) are seen in a relatively small area northward of $50^{\circ} \mathrm{N}$, suggesting that the effect of global warming is generally small. However, the western and eastern coastal regions of the U.S.A. show exceptionally large positive values, which might suggest a strong impact of the recent warming in urbanized regions. In contrast, less urbanized regions in midlatitudes are generally dominated by negative values. Large negative values less than -0.2 wpy are seen not only in the mountainous regions in eastern Europe and central Asia but also in the eastern Tibetan Plateau and Rocky Moun- tains. Since the earlier start of the snow-cover season is unlikely to be directly related to global warming, the negative trends of the date of first snow cover might reflect a possible change in the regime of the atmospheric general circulation.

The geographical distribution of the linear trends of the date of last snow cover is shown in Figure 8. Clearly, the map is dominated by negative values over almost the entire hemisphere (northward of $30^{\circ} \mathrm{N}$ ) with very few exceptions. In particular, high mountain regions in mid-latitudes show very strong negative tendencies: the date of last snow cover is advanced by about 0.3 wpy in central Asia and the Rocky Mountains, and by nearly 0.5 wpy in the Tibetan Plateau. Fallot and others (1997) reported that snow depths in central Asia in the former Soviet Union are sensitive to temperature variations, and then it is likely that the earlier snowmelt may be an indication of the decrease in snowfall amount owing to global warming.

Finally, the geographical distribution of the linear trends of the length of a snow-cover season is shown in Figure 9. Clearly, the snow-cover duration is decreasing in almost all regions except the eastern part of Europe and the western part of the Siberian Plain. Roughly speaking, the decreasing rate is $<0.1$ wpy in high-latitude plains, about 0.2 wpy in the Scandinavian Peninsula and Rocky Mountains, and about 0.3 wpy in the western Tibetan Plateau. In the Siberian Plain and in the Northwest Territories of Canada, this decrease in snow-cover duration results primarily from earlier snowmelt in springtime (Fig. 8) and secondarily from delayed snow accumulation in early winter (Fig. 7). In high-elevation regions in mid-latitudes, the rate of advance of the last snow-cover week is larger than that of 


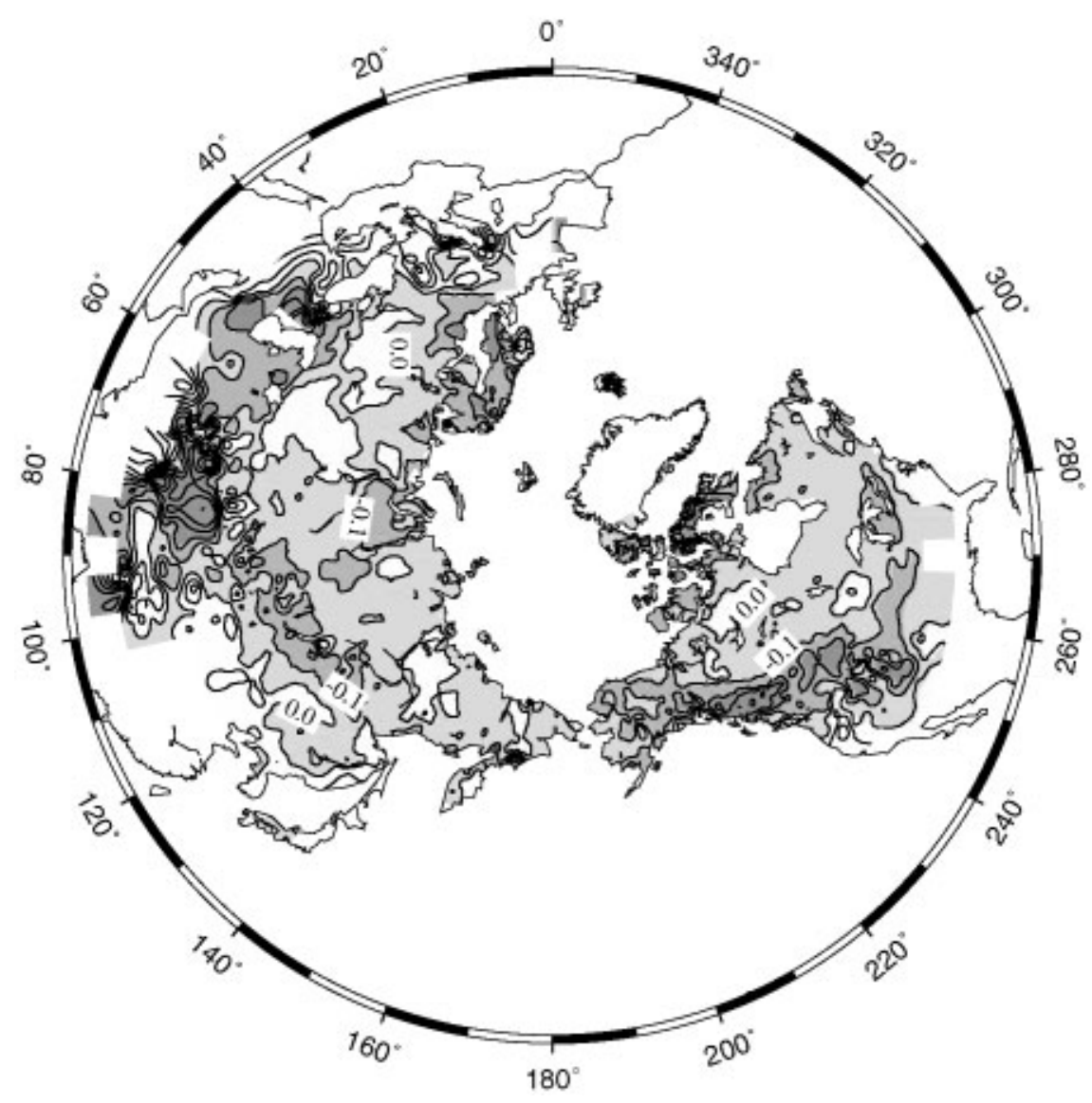

Fig. 9. Geographical distribution of the linear trends of the length of a snow-cover season. Isopleths are given at intervals of 0.1 wpy. The areas with the values 0.0 to $-1.0,-0.1$ to -0.2 , and $<-0.2$ are shaded lightly, moderately and heavily, respectively, while the area with positive values is not shaded.

the first snow-cover week, which results in the decrease in snow-cover duration. In eastern Europe and the western part of the Siberian Plain, on the other hand, the snow-cover duration increases slightly owing to delayed snowmelt, though the result is not statistically reliable.

\section{CONGLUDING REMARKS}

The dataset of the the Northern Hemisphere EASE-Grid weekly snow cover and sea-ice extent for the period September 1972-August 2000 has been analyzed statistically in order to examine the possible effect of global warming on the seasonal change of snow cover. Attention is focused on the decadal change of total snow-cover area and the linear trend of the seasonal snow-cover parameters. The main conclusions obtained are as follows.

(1) The total snow-cover area in the 1980s and 1990s has decreased by about $3 \times 10^{6} \mathrm{~km}^{2}(6 \%)$ compared with the 1970s. In general, snow accumulation has been delayed by about 1 week, the snowmelting has advanced by about 2 weeks, and the length of a snow-cover season has decreased by $2-3$ weeks. In addition, the maximum snow-cover area during January-February has gradually decreased by about $3 \times 10^{6} \mathrm{~km}^{2}$ within the two decades.

(2) Geographically, the decreasing rate of snow-cover duration is very weak ( $<0.1 \mathrm{wpy})$ in high-latitude regions such as the Siberian Plain and the Northwest Territories of Canada, while it is >0.2wpy in high-elevation regions such as the Scandinavian Peninsula, Tibetan
Plateau and Rocky Mountains. For most regions the contribution from earlier snowmelt is greater than that from delayed snow accumulation. The reason for the earlier snowmelt may be that total snowfall amounts in the high-elevation regions have decreased owing to global warming.

Obviously, the snow-cover extent is a good indicator of global warming. According to the IPCC report (Houghton and others, 1996), the effect of global warming would be more significantly realized in the Arctic regions if the $\mathrm{CO}_{2}$ in the atmosphere were doubled. For the present, however, the influence of the recent global warming on the seasonal change of snow cover is seen more clearly in mid-latitudes than high latitudes.

On the other hand, high mountains are able to capture water vapor from the atmosphere and hold it as snow cover until the snow is melted away in spring and summer. Therefore, the snow cover in the high mountain regions is a source of fresh water for our daily lives, agriculture and industry. That snow is melting earlier implies that the earth's ability to store fresh water as snow cover is declining owing to global warming. This could be a serious problem for ensuring water resources in the 21st century. It is therefore very important to continue monitoring the long-term changes in snow-cover extent.

\section{ACKNOWLEDGEMENTS}

The authors would like to express their appreciation to the staff of the NSIDG who compiled and distributed the 
important dataset of the Northern Hemisphere EASE-Grid weekly snow cover and sea-ice extent.

\section{REFERENCES}

Armstrong, R. L. and M. J. Brodzik. 2001. Recent Northern Hemisphere snow extent: a comparison of data derived from visible and microwave satellite sensors. Geophys. Res. Lett., 28(10), 3673-3676.

Brown, R. D. 2000. Northern Hemisphere snow cover variability and change, 1915-97. 7. Climate, 13 (7), 2339-2355.

Fallot, J. M., R. G. Barry and D. Hoogstrate. 1997. Variations of mean cold season temperature, precipitation and snow depths during the last 100 years in the former Soviet Union (FSU). Hydrol. Sci. F., 42(3), 301-327.

Foster, J., M. Owe and A. Rango. 1983. Snow cover and temperature relationships in North America and Eurasia. 7. Climate Appl. Meteorol., 22(3), 460-469.

Groisman, P.Ya. and D. R. Easterling. 1994. Variability and trends of total precipitation and snowfall over the United States and Canada. 7. Climate, 7(1), 184-205.

Gutzler, D. S. and R. D. Rosen. 1992. Interannual variability of wintertime snow cover across the Northern Hemisphere. 7. Climate, 5(12), 1441-1447.
Hahn, D. G. and J. Shukla. 1976. An apparent relationship between Eurasian snow cover and Indian monsoon rainfall. 7. Atmos. Sci., 33, 2461-2462.

Houghton, J. T., L. G. Meira Filho, B. A. Callander, N. Harris, A. Kattenberg and K. Maskell. 1996. Climate change 1995: the science of climate change. Cambridge, etc., Cambridge University Press.

Iwasaki, T. 1991. Year-to-year variation of snow-cover area in the Northern Hemisphere. 7. Meteorol. Soc. Jpn, 69(2), 209-217.

Karl, T. R., P.Ya. Groisman, R.W. Knight and R. R. Heim, Jr. 1993. Recent variations of snow cover and snowfall in North America and their relation to precipitation and temperature variations. f. Climate, $\mathbf{6}(7), 1327-1344$.

Kripalani, R. H. and A. Kulkarni. 1999. Climatology and variability of historical Soviet snow depth data: some new perspectives in snow-Indian monsoon teleconnections. Climate Dyn., 15(6), 475-489.

Leathers, D. J. and D. A. Robinson. 1993. The association between extremes in North American snow-cover extent and United States temperatures. 7. Climate, 6(7), 1345-1355.

Oerlemans, J. 2001. Glaciers and climate change: a meteorologist's view. Lisse, etc., A. A. Balkema Publishers.

Robinson, D. A. and K. F. Dewey. 1990. Recent secular variations in the extent of Northern Hemisphere snow cover. Geophys. Res. Lett., 17 (10), 1557-1560.

Robinson, D. A., K. F. Dewey and R. R. Heim, Jr. 1993. Global snow cover monitoring: an update. Bull. Am. Meteorol. Soc., 74 (9), 1689-1696. 